\title{
Microstructure of Powder Metallurgy Components
}

\author{
George F. Vander Voort1 and Elena P. Manilova2
}

1 Buehler Ltd, 41 Waukegan Road, Lake Bluff, Illinois, USA

2 Polzunov Central Boiler and Turbine Institute, Politechnicheskaya str. 24, St. Petersburg, Russia

Metallographic specimen preparation of powder metallurgy $(\mathrm{P} / \mathrm{M})$ materials presents problems when the material is not compacted to full density by hot-isostatic pressing. Some alloys are processed to full density, for example, high-speed steel tool steels, nickel-base superalloys and Co-based alloys used for implants. But, many $\mathrm{P} / \mathrm{M}$ metals and alloys contain a considerable void content. Powders exhibit low degrees of segregation due to the fine droplet size and fast solidification rate. These characteristics are highly desirable when making highly alloyed high-speed tool steels where carbide segregation in ingot-cast alloys greatly reduces tool life. In comparison, the $\mathrm{P} / \mathrm{M}$ versions of the same grades have very fine, well-distributed carbides and substantially outperform ingot cast material. While the powder has a very fast solidification rate and low segregation, if it is not processed to full density, the pre-alloyed powder is generally not made to the composition desired in the final product. Instead, it is blended with powder particles of various alloying elements, e.g., nickel, and carbon is added as graphite particles. Thus, upon sintering, the structures are quite heterogeneous and contain substantial void content.

The heterogeneity of the non-fully dense powder products, the void content and the possibility of having elemental copper in the matrix all make specimen preparation difficult. On the other hand, specimen preparation of fully dense tool steels, nickel-based superalloys and Co-based alloys is usually easier than their wrought equivalents, due to their greater homogeneity. Hence, some P/M products are harder to prepare while others are easier. Etching of specimens with voids and heterogeneous microstructures is more difficult, particularly in controlling bleed-out from the voids, Fig. 1. Such specimens can be vacuum impregnated with a low-viscosity epoxy to minimize bleed out problems. If the voids are filled with epoxy, then it is easier to prepare them and reveal the correct void content and size as the epoxy supports the void walls. Figures 2-4 illustrate the heterogeneity of $\mathrm{P} / \mathrm{M}$ products.

Specimen preparation of Fe-based non-fully dense $\mathrm{P} / \mathrm{M}$ products can be accomplished readily using modern approaches. After mounting (vacuum impregnation with a low-viscosity epoxy is a good practice, although not a necessity), grind the specimens using a relatively fine grade of SiC paper, such as 240-grit (P220 or P280 in the FEPA system). Then, use napless, woven cloths for the polishing steps with diamond abrasive. Silk, nylon or polyester cloths, or chemotextile pads, are recommended. Two steps, using 9 - and $3-\mu \mathrm{m}$ diamond are usually adequate. For very difficult grades, add a $1-\mu \mathrm{m}$ step. It is best to charge the cloth with diamond paste and then add the appropriate lubricant. If the step is several minutes long, add the same size diamond in slurry form to maintain a high cutting rate. To yield a scratch-free finish with best sharpness, use either a medium nap synthetic suede cloth or a polyurethane cloth for the final step with either colloidal silica or alumina abrasives with a particle size of about $0.05-\mu \mathrm{m}$. Table 1 illustrates a method that we have used successfully. 
Table 1. Preparation Method for Fe-Based P/M Products

\begin{tabular}{|c|c|c|c|c|}
\hline Surface & Abrasive & $\begin{array}{c}\text { Pressure/Specimen } \\
\text { Lb }(N)\end{array}$ & $\mathrm{rpm}$ & $\begin{array}{c}\text { Time } \\
\text { Minutes }\end{array}$ \\
\hline $\begin{array}{c}\text { Waterproof paper } \\
\text { with adhesive }\end{array}$ & $\begin{array}{c}\text { 240-Grit SiC } \\
\text { (water cooled) }\end{array}$ & $6(27)$ & $240-300$ & Until Plane \\
\hline UltraPol silk cloth & $\begin{array}{c}9-\mu \mathrm{m} \text { diamond with } \\
\text { lubricant }\end{array}$ & $6(27)$ & $120-150$ & 5 \\
\hline $\begin{array}{l}\text { TriDent polyester } \\
\text { cloth }\end{array}$ & $\begin{array}{c}\text { 3- } \mu \mathrm{m} \text { diamond with } \\
\text { lubricant }\end{array}$ & $6(27)$ & $120-150$ & 4 \\
\hline $\begin{array}{l}\text { MicroCloth napped } \\
\text { cloth }\end{array}$ & $\begin{array}{l}\text { MasterPrep } \\
\text { Alumina } \\
\text { suspension }\end{array}$ & $6(27)$ & $100-150$ & $1-3$ \\
\hline
\end{tabular}
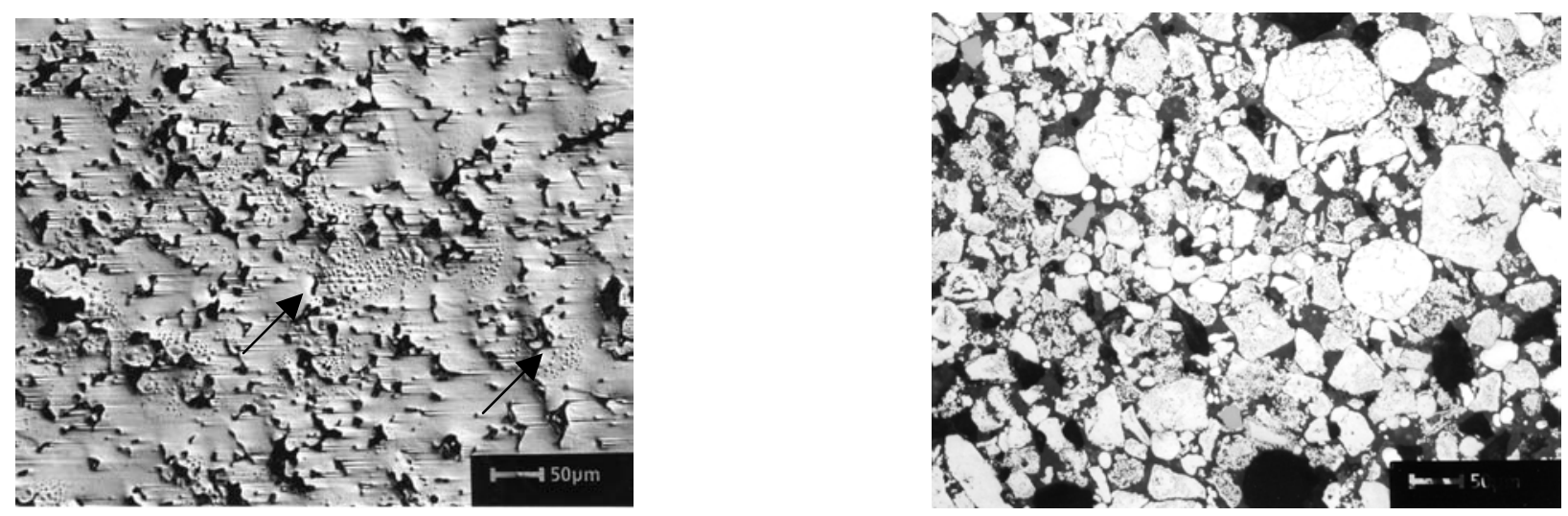

Figure 1 (left). "Comet tails" produced using manual polishing for the final step (DIC). Note also bleed-out (arrows) from inadequate drying.

Figure 2 (right). Compacted, non-sintered $\mathrm{Cu}-10 \% \mathrm{Sn}-1 \%$ graphite specimen showing pore shapes (as-polished, not etched).
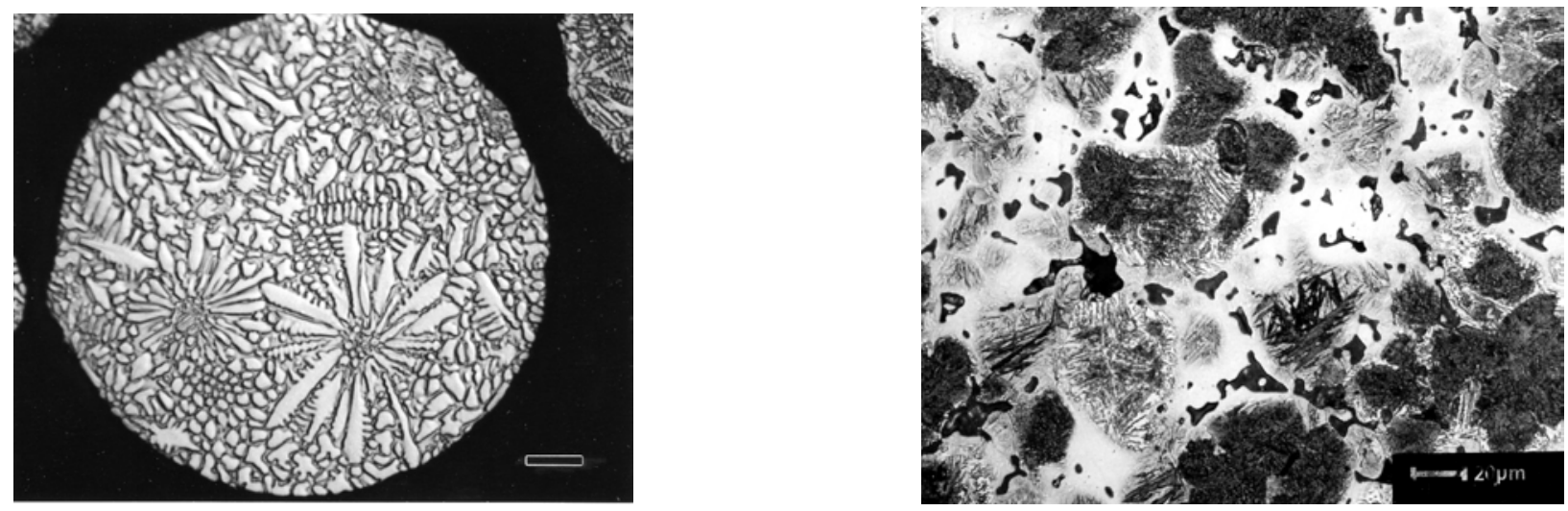

Figure 3 (left). As-cast Dendritic structure of Co-Cr-Mo powder $\left(90 \mathrm{HCl}-10 \mathrm{H}_{2} \mathrm{O}_{2}, 3 \%\right.$ conc.; bar is $10 \mu \mathrm{m})$

Figure 4 (right) Heterogeneous microstructure of as-sintered $\mathrm{Fe}-0.85 \% \mathrm{Mo}-6 \% \mathrm{Ni}-0.5 \%$ graphite compact ( $2 \%$ nital). 